\title{
The Impact of Job Satisfaction and Work Environment Friendly on Services Innovation with Mediator Role of Knowledge Sharing in Companies under Supervision of Parstousheh in Gilan Province
}

\author{
Maryam Pak TARIGH ${ }^{1}$, Forugh Rudgar NEZHAD ${ }^{2}$ \\ ${ }^{1}$ Department of Public Administration, Islamic Azad University, International Branch, \\ Bandar Anzali, Iran \\ Maryampaktarigh@gmail.com
}

${ }^{2}$ Assistant professor, Department of Management, Islamic Azad University ,Bandar Anzali Branch, Iran.

\begin{abstract}
Nowadays the complexity of competitiveness, innovation as one of the main advantages of survival of company considered. According to the needs of employees and needs to create satisfaction and improve the quality of life of employees and satisfaction, efficiency and effort will lead to more and better work efficiency. The present paper examines the relationship between the environment friendly concept and job satisfaction on service innovation has examined the mediating role of knowledge sharing. Friendly work environment and job satisfaction influenced the conceptual model shown on knowledge sharing. Moreover, the sharing of knowledge on service innovation and increased innovation services of company. The study aimed to investigate the impact of job satisfaction and work environment friendly on services innovation with mediator role of knowledge sharing in companies under supervision of Parstousheh in Gilan province. The population consisted of 16 companies under supervision of Parstousheh in Gilan province is chosen randomly. The tool measuring is standard questionnaire and 285 questionnaires were distributed. After collecting the questionnaires to assess the reliability of Cronbach's alpha for each of the components of a friendly work environment, job satisfaction, knowledge sharing and innovation services were used.
\end{abstract}

Keywords: job satisfaction, friendly work environment, knowledge sharing, service innovation

\section{Introduction}

Today, the most important organizational asset, knowledge can access it. Organizations can be successful who can most useful, the most authoritative and up to date of human knowledge in the areas of their business, and they use it efficiently. The sharing of knowledge considered as a complex activity, but value creator, the foundation of many organizational strategies (Mansoori et al., 2011). According to Peter Drucker, the founder of the twenty-first century to money, capital and even technology but is knowledge (Drucker, 2000). The success criteria of the intellectual capital create competitive advantage for its exclusivity and the ability to use intellectual capital and knowledge processing. It facilitates the exchange of knowledge and information as one of the basic processes of knowledge management in organizations today. Knowledge-sharing activities include transmission and distribution of knowledge (implicit and explicit) of a person, group or organization to a person, group, or other organization (Lei et al, 1999). 
Recent research confirmed that many friends are not the result of formal communication within the institutional framework will be preserved for many employees. In addition to being an important part of the process of creating friendships are human values, the attitudes and behaviors of individual employees who are friend and comrade, are affected. These results could potentially reduce the self-interest of the individual, reduces the negative attitudes of employees. Thus highlighting the importance of friendship aspect has become for the success of most organizations. Friendship is a unique aspect of the work environment (Mahdian, 2010). One of the most important and perhaps the most controversial concepts on the one hand and theoretical efforts made fundamental priority and on the other hand, at all levels of management and human resources of organizations has gained importance is job satisfaction. Job satisfaction affects many organizational variables (Kharazi et al., 2013).

Today some stability in the workplace, rather than to instability and uncertainty and traditional industries are replaced by new ones have been lost and developed. As part of the service sector productivity is increasing day by day and its activity is increased, which can be significantly influenced the innovation processes. Therefore, proper management and direction of innovation and creativity become more importance (Doyle and Bridgewater, 1988).

\section{Background Research}

Kuo et al. (2014) in an article entitled enable innovative capabilities: sharing knowledge as a mediator. The purpose of this paper is to examine the relationship between job satisfaction, friendly work environment, and knowledge sharing and innovation services.

This is an experimental study that aims Electronic Information Engineering Sciences in parts located in Taipei, Taiwan and Hsinchu ( $\mathrm{n}^{1 / 4851)}$, using a questionnaire to gather data to test the relationship between the four dimensions. The results showed that: First, both job satisfaction and work environment friendly services have shown a significant effect on innovation. Second, knowledge sharing has significantly the effect of job satisfaction and work environment friendly to innovation services. This study adds value by examining the moderating effect of sharing knowledge. Results can be strategic planning, human resources development to enhance the capabilities help service innovation in the technology industry (Kuo et al, 2014). Amayah in year (2013) study entitled factors influencing knowledge sharing is done in public sector organizations. The purpose of this paper is to examine the factors that affect knowledge sharing in an organization that puts the public sector. Paper is quantitative research. Data were collected through questionnaires and were analyzed using multiple regressions. Community concerns, considerations of principle and self-interest are three drivers found to have a unique contribution to the variance in knowledge sharing. Social interaction, rewards, and organizational support: the empowerment significant main effect was to share knowledge. Two obstacles, courage and the degree of empathy, the organizational climate measurements, has a significant main effect was found in sharing knowledge. Engage in normative social interaction, personal interests, organizational support, and consideration of the principles by the courage, moderating effect on the relationship between the factors motivating and share knowledge. This study in public sector organizations only, which limits the generalizability of the findings to other settings was done. Another limitation is that the attitude towards knowledge sharing, and knowledge-sharing behaviors is across different cultures (Amayah, 2013). Melton and Hartline in the year (2015) as customer and employee research services to create radical innovations have done. This study shows that 
companies can effectively involve customers in the development of new services (NSD) to create radically innovative, new services with high performance. Previous studies have shown no effect on radicalism customer participation in the development of new services, but this study is evidence that customer involvement in the design stage of new service development projects can increase radical innovation provides a new service. The survey of 160 enterprises in the development process, the participants and the results of recent projects of innovation in services has been arrested. In addition, brokered direct effect hypotheses were tested using structural equation modeling. Customer participation in the development process of new services innovation has a new service that customers engaged in the design phase and when penetrated by due process complexity. Customer participation in the development stages has a significant effect on service innovation. The complexity of the process also because of the positive effects of front-line employees and engage cross-functional team in the development of new services in the services innovation (Melton and Hartline, 2015). In 2010, a study entitled a review on friendship written by Mahdian work. This paper aims to study the concept of friendship preparatory work and in particular generalizing the scale friendliness of the environment through data provided by 359 respondents from five different countries. The results of this study show that workplace friendships multi-scale factor in terms of period, there is a lack of recognition and communication (Mahdian, 2010).

Danaeefard et al (2011) as an open investigation on the promotion of knowledge sharing in light of organizational citizenship behavior examined. The study of the relationship between organizational citizenship behavior and knowledge sharing government agencies in the Ministry of Transportation and Housing and Urban Development is studied. The study population consisted of 662 employees at two levels of management staff and experts in the ministry are mentioned. 248 Minimum sample sizes in this study are that the researcher's generalizability of the findings, $15 \%$ of them said. To gather data for this study from two questionnaires organizational citizenship behavior questionnaire and sharing knowledge from a research organization Mousakhani used.

Independent T-test data analyzed using Pearson correlation and linear regression tested. The results of the tests showed that the correlation between organizational citizenship behavior and its dimensions (except gentleman) and knowledge sharing at $99 \%$ there is a positive correlation. The results of regression analysis showed that independent predictors of variance in knowledge sharing (OCB) are $18.4 \%$. It was also found a significant difference in two ministries in terms of organizational citizenship behavior and knowledge sharing (Danaeefard et al, 2011).

\section{Materials and methods}

The study population consisted of Parstousheh company, whose number is 16 participants were selected by simple random sampling and to determine the sample size in this study is used Morgan and the number of samples for the frequency has 790 employees, 260 employees has introduced. The 285 questionnaires were distributed, which has 265 questionnaires were returned. In this study is to evaluate and compare the results obtained by questionnaire from a distance of 5-item Likert scale was used to measure the variables. The data in the present study using documentary (library) and field. Therefore, in this research is firstly to analyze the data, using descriptive statistical methods to sample attributes discussed. The next step is to analyze the data is analyzed using statistical techniques. Data analyzed using SPSS and AMOS. Pearson, confirmatory factor analysis and structural equation model for statistical analysis was used. 


\section{Research Findings}

Descriptive indicators of the variables provided and in Table 4-1 were shown.

Table 4-1: Descriptive indicators of the variables in study

\begin{tabular}{|l|l|l|l|l|l|l|}
\hline \multicolumn{1}{|c|}{ Variable } & Average & \multicolumn{1}{|c|}{$\begin{array}{c}\text { Standard } \\
\text { deviation }\end{array}$} & Skewness & Elongation & $\begin{array}{c}\text { Z Kolmogorov - } \\
\text { Smirnov }\end{array}$ & SIG \\
\hline Job Satisfaction & 3.40 & 1.15 & $0.82-$ & $0.06-$ & 0.05 & 0.03 \\
\hline Workplace & 3.18 & 1.16 & $0.73-$ & $0.68-$ & 0.12 & 0.001 \\
\hline $\begin{array}{l}\text { Sharing } \\
\text { knowledge }\end{array}$ & 3.45 & 1.29 & $0.68-$ & $0.79-$ & 0.17 & 0.001 \\
\hline Innovation & 3.62 & 1.30 & $0.80-$ & $0.62-$ & 0.12 & 0.001 \\
\hline
\end{tabular}

\section{4-1- Measurement model test}

Goodness scale of fit of this study is shown in Table 4-2. This chart shows the data of this study and factor structure of this scale, goodness fit and this show alignment of these questions with a scale structures.

Table 4.2 Characteristics of goodness of fit-scale in study

Characteristic Estimatin

Proportion to the degree of freedom chi-square (X2 / df)

2.54

The square root of the variance estimation error of approximation (RMSEA)

Fit index (GFI)

0.91

Adjusted index goodness of fit (AGFI)

0.90

\section{4-3- Testing the structural model (theoretical model and hypothesis testing)}

Given the fact that the correlation matrix for the analysis of causal models, especially structural equation modeling, so before we get to test the theoretical model, the correlation matrix of variables with significant correlation coefficients and levels presented in Table 4.3 to the relationship between the variables examined.

Table 4-3: Correlation matrix of variables

\begin{tabular}{|c|c|c|c|c|c|}
\hline No & Variable & 1 & 2 & 3 & 4 \\
\hline 1 & Job Satisfaction & 1 & & & \\
\hline 2 & Workplace & $* * 0.67$ & 1 & & \\
\hline 3 & $\begin{array}{c}\text { Sharing } \\
\text { knowledge }\end{array}$ & $* * 0.56$ & $* * 0.48$ & 1 & \\
\hline 4 & Innovation & $* * 0.64$ & $* * 0.66$ & $* * 0.53$ & 1 \\
\hline$* \mathrm{p}<0.05, * * \mathrm{p}<0.01$
\end{tabular}

Results of table above shows each of the variables for two and two together and at 0.01 has significant relationship. For example, the relationship between organizational structures with knowledge management is 0.62 .

\section{4-3-1-Testing a theoretical model in study}


In the current study knowledge management structures endogenous model, friendly work environment, knowledge sharing, job satisfaction and innovation model is exogenous structures, model test results are shown in Figure 4-1.

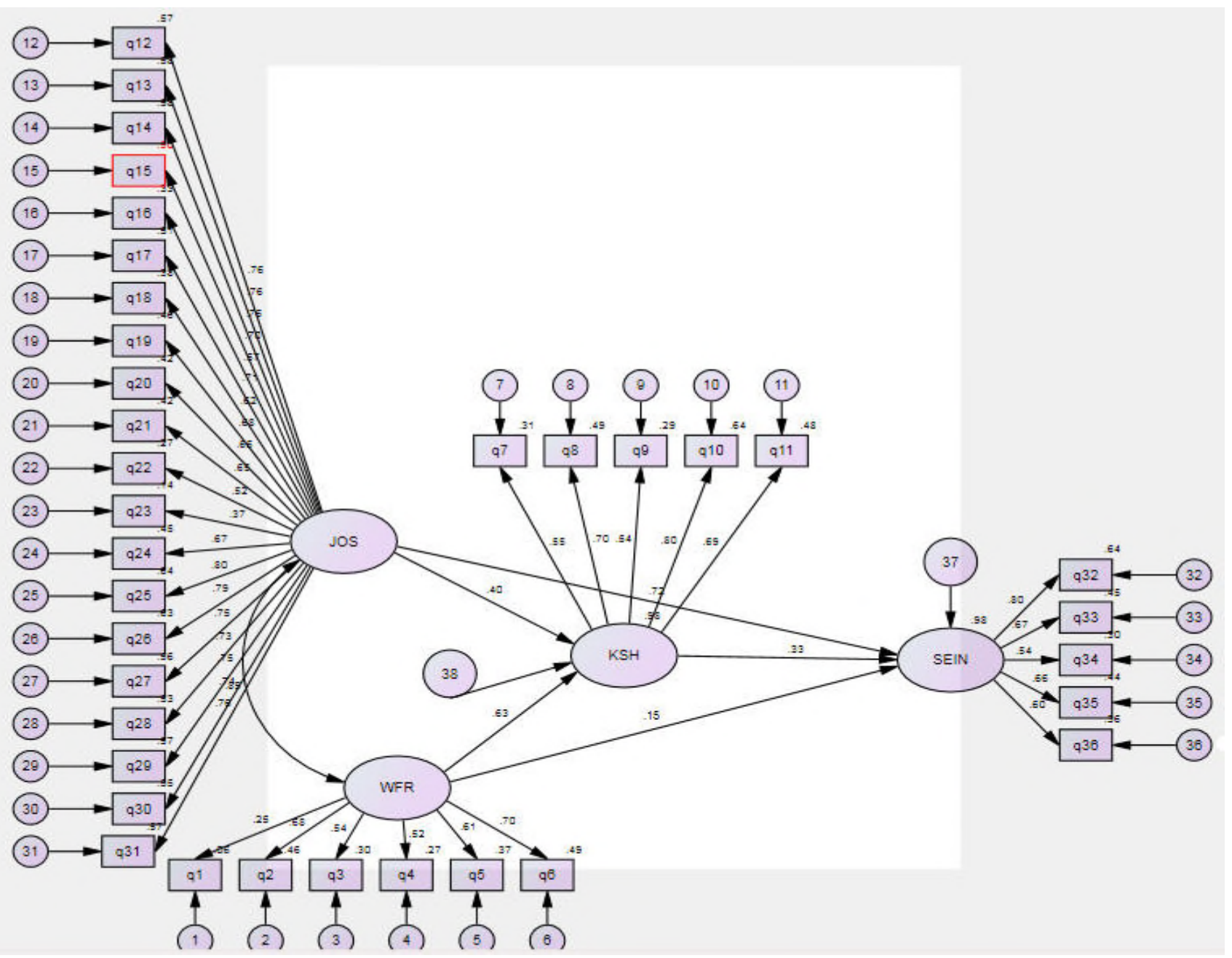

Figure 4-1: Test version of the study

\subsection{2-Testing research hypotheses}

The present study tested the model in Figure 4-1 is shown in standard mode. Also in Table 4-4, the coefficients of direct, t-statistic significant level of each route and directions have been reported. 
Table 4-4: Estimated coefficients of direct effects (testing hypothesis)

\begin{tabular}{|l|l|l|l|l|l|l|}
\hline Hypothesis & \multicolumn{1}{|c|}{ Routes } & Path coefficie & T statistic & Sig & $\mathrm{R}^{2}$ & Result \\
\hline & Innovation workplace & - & - & - & 0.69 & - \\
\hline 1 & Job Satisfaction & 0.72 & 0.16 & 0.001 & - & Supported \\
\hline 2 & Friendly workplace & 0.15 & 1.57 & 0.001 & - & Supported \\
\hline 3 & Sharing knowledge & 0.33 & 0.28 & 0.001 & - & Supported \\
\hline & knowledge sharing & - & - & & 0.68 & - \\
\hline 4 & Job Satisfaction & 0.40 & 3.38 & 0.001 & - & Supported \\
\hline 5 & Friendly workplace & 0.63 & 4.53 & 0.001 & - & Supported \\
\hline
\end{tabular}

Results Table 4.4 shows that job satisfaction index (0.72), friendly work environment $(0.15)$ and knowledge sharing (0.33) could innovate to 69 percent anticipate, as well as the results show that job satisfaction has a direct ratio $(0.40)$ and friendly work environment by a factor of (0.63) to 68 percent cannot predict knowledge sharing.

\section{4-3-3 Indirect effects}

In Table 4.5 the results of the indirect effects in the form of the mediating role of knowledge sharing in the relationship between job satisfaction, work environment friendly and innovation shown.

Table 4-5: Estimated coefficients indirect effects (role of mediator)

\begin{tabular}{|c|c|c|c|c|c|c|}
\hline Hypothesis & Routes & Path coefficie & T statistic & Sig & $\mathrm{R}^{2}$ & Result \\
\hline & Innovation workplace & & & & 0.76 & \\
\hline 6 & Friendly workplace & 0.26 & 3.34 & 0.001 & & Supported \\
\hline 7 & Job Satisfaction & 0.14 & 3.56 & 0.001 & & Supported \\
\hline
\end{tabular}

According to the table above, the mediating role of knowledge sharing in relations between friendly work environment, job satisfaction, and innovation is confirmed.

\section{4-3-4- Fit model test}

Then, in Table 4-6 the results of the present study was fitting indicators. According to the criteria that Giffen et al (2000) have proposed a model of good fit with the data collection is tested.

Table 4-6: Indicators of overall fit of the model test study

\begin{tabular}{|c|c|c|c|c|c|c|}
\hline $\mathrm{X} 2$ & $\mathrm{df}$ & X2/d.f. & CFI & GFI & AGFI & RMSEA \\
\hline 2035.1 & 588 & 3.46 & 0.96 & 0.95 & 0.91 & 0.05 \\
\hline
\end{tabular}

Results Table 4-6 shows that the model is suitable for all index review, this result shows that the model tested the study hypothesis of the research is consistent with the data collected, on this basis we can say, the model proposed in the study of theoretical and practical support and can be used by other researchers.

\section{Conclusion}

In general, knowledge management is the organization of knowledge. The attempt to acquire the required knowledge, sharing of information within an organization and emphasis on strengthening the organizational memory to improve the decision-making process, increase production and encourage people to innovate in the organization. At the 
heart of the search for knowledge management innovation is because sustainable competitive advantage in innovation hidden. The organization created the atmosphere in which emphasized that the exchange of explicit knowledge and innovation so that employees are more likely to share their new knowledge with each other and have their application. Open and speed of change around the world makes that creativity is more important than before. Only countries with innovation and creativity themselves adapt and keep pace with changes in the process. It is obvious that in today's complex world, organizations are more successful in competition with others leading opportunity to take the best advantage and this is not possible except by increasing creativity and innovation. Since the services are often complex and less expertise of technologies, processes used, ability to copy the innovation, and every innovation organization is very large and profitable only for a special period is applicable. The organization therefore will be able to survive in the long run and have profitability, the first strategy is to support the right of employees to attract innovative activities, and second, foster and promote the creativity of their work with the organization to provide growth. Workplace friendships are aimed more creativity who informed decisions related to businesses that improve customer service and quality will provided. Job satisfaction is an important factor in increasing productivity and organizational commitment taken into account. In multiple studies, found that job dissatisfaction is associated with absence from work. Along the absence of job turnover that occurs, as well as staff complaints show job dissatisfaction. The purpose of this study, the impact of job satisfaction and work environment friendly to innovation services and the mediating role of knowledge sharing in companies under supervision of Parstousheh in Gilan province.

\section{Research proposal}

The results show that, first of all, increase job satisfaction and friends from work can ease the ability to be innovative organizational services. Job satisfaction is in fact a personal need that every employee tries to follow it. Job performance are of satisfactory quality, ease, and which subsequently will be to support innovation. In addition, since the friends from work could affect service innovation, it is recommended that interactive relationship management among employees develop, it's time to enhance trust and reciprocity at work, it is possible to effectively reduce conflicts inefficient and foster a healthy environment for new ideas are created. Second, knowledge sharing services to be considered as a catalyst for innovation. In fact, it is the value of human capital in a knowledge economy developed. However, people have limited knowledge and experience. In fact, the components of knowledge sharing, creativity and new knowledge of employees is included turmoil failure to complete individual will and the knowledge to maximize the benefit through individual and organizational performance will be better. According to the results of the research proposals and hypotheses considered are as follows:

1. It is suggested that the emotions that person's job satisfaction than his job is shed. A person with a sense of job satisfaction and positive person who is unhappy with his job, negative feelings towards the job; job satisfaction also led to new ideas with innovation in services that generate new product is a direct relationship between the increase in job satisfaction increases innovation.

2. It is recommended that a friendly work environment that enhances participation in an organization. In addition, cooperation between people increases the direct contact with service innovation. 
3. According to the third hypothesis suggests that knowledge sharing that same knowledge can be exchanged between people in the organization and direct contact with service innovation that increases the production of new products.

4. It is suggested that job satisfaction is not the same satisfaction that the job in the organization with knowledge sharing that same knowledge can be exchanged between people in the organization have direct connections.

5. According to the fifth hypothesis is suggested that people in the organization, job satisfaction, work environment friendly to their jobs with the direct connections and higher the level of job satisfaction more people to be able to create a friendly work environment among more people.

6. It is suggested a friendly working environment indirectly through service innovation through knowledge sharing with new products and ideas to communicate product.

7. It is suggested that job satisfaction indirectly through service innovation through knowledge sharing with new products and ideas to communicate product.

\section{Suggestions for Future Research}

- The relationship between job satisfaction and knowledge sharing

- The relationship between friendly work environments by sharing knowledge

- The relationship between job satisfaction and service innovation

- The relationship between work environment friendly to innovation services

- The relationship between knowledge sharing and service innovation

- A model of job satisfaction and work environment friendly to share knowledge in companies under supervision of Parstousheh in Gilan province

\section{References}

- Kharrazi, Kamal; Mirkamali, Mohammad, Torki, A., (2013), servant leadership and job satisfaction of employees, prospects of Public Administration, number 14

- Danaeefard, H, Khaef Ellahi, Ahmad Hosseini, M., (2011), reflection on the promotion of knowledge sharing in light of organizational behavior, public management research, Issue XIV

- Mansouri, H., Taheri Demneh, M, Konjkav Fard, AR, (2011); assess the impact of knowledge management strategy on human resources management practices in academic libraries and higher education institutions using the approach, BSC, Journal of Information Processing and Management, Vol. twenty-Issue 1 (67)

- Mahdian, H., (2010), Review on workplace friendships, wisdom, No. 219.

- Amayah, A.T., (2013), "Determinants of knowledgesharing in a public sector organization", Journal of Knowledge Management, Vol. 17 Iss: 3.

- Doyle ,P and Bridgewater, S .(1988)," Inovation in marketing “, The chartered Institute of marketing, Elsevier Butter worth Heinemann .Oxford.

- Drucker, P. F. (2000). Knowledge Work. Executive Excellence. 17(4). 11-12.

- Kuo, Y.K., Kuo, T.H., Ho, L.A., (

- 2014), "Knowledge sharing, intellectual capital and firm performance", Management Decision, Vol. 52 Iss 2.

- Lei, D. ; J. Slocum\&R. Pitts. (1999). Building Competitive Advantage: Managing StrategicAlliances to Promote Organizational Learning. The Journal ofWorld Business. 23(3). 203-204. 
Bulletin de la Société Royale des Sciences de Liège, Vol. 85, 2016, p. 1017 - 1025

- Melton, H., Hartline, M.D.,(2015), "Customer and employee co-creation of radical service innovations", Journal of Services Marketing, Vol. 29 Iss: 2. 